\title{
Tourism Informatization Research under the Mode of Internet of Things
}

\author{
Gangzhi Guo
}

School of Culture and Tourism, Yiwu Industrial and Commercial College, Yiwu Zhejiang, 322000, China

Keywords: lot mode, RFID, Scenic spots, Informatization mode, Tourism resources.

\begin{abstract}
In the era of Internet of things (hereafter referred to iot), tourism should take the government iot development planning as the guide to formulate its own strategic development plan. At the same time it should speed up the innovation and reform of tourism products and services to realize the informatization management of tourism industry. The article first discusses the design of the scenic spots informatization solution under iot mode. On this basis it conducts in-depth analysis on the application of RFID technology in scenic spots, iot monitoring system in scenic spots and tourist traffic informatization under iot mode in succession. The article has some reference values.
\end{abstract}

\section{Introduction}

Iot is a kind of new derivative developed from internet of computer in the science and technology era as well as the main trend of development of network industry in the future. Iot mainly adopts RFID(Radio Frequency Identification) technology to identify goods or things to realize interaction and sharing of information. It has technical characteristics of intelligent processing, reliable transmission and all-round awareness. Internet of things is a blend of a number of advanced technologies including wireless communication network technology, transmission technology, sensor technology, data storage, data processing and so on. In terms of item identification, the most representative technology of iot is RFID. RFID can be called as the "identity card" of things. It is both the foundation and the core of the whole operation system of iot, playing a very important function role.

Tourism and its affiliated industry have formed a tight system as a whole. This kind of system has high openness. It usually involves tourists' accommodation, food, travel, etc. in addition to including tourism scenic spots in the center position themselves. The modern tourism concept is different from the tourism of the traditional sense. It pays attention to and emphasizes the interoperability travel pattern with across departments as well as across industries. For example, what "food"'accommodation"'going out" in tourism industry system refer to are respectively the restaurant industry, hotel industry and transportation industry. With the rapid development of economy, people's material and spiritual life level is increased day by day, under this context, "food" has gradually developed into an important resource in modern tourism and formed a special tourism affiliated resources products by establishing its own system. Under the mode of iot, subsystems of tourism catering industry system mainly include telephone/Internet reservation system, food traceability management system, food management system and mobile order charge system etc; iot informatization of tourist hotel industry is mainly embodied in two aspects, the hotel's comprehensive wireless network coverage and One-Card of the hotel; iot informatization of tourist traffic industry is mainly embodied in public transportation informatization and car rental informatization. Among them the public transportation informatization is mainly embodied in two aspects, the tourism vehicle management and ticketing system, while car rental informatization is mainly embodied in aspects of tourism vehicle management, ticketing system, renting and returning car system, tourist vehicles monitoring and tracking and member management system etc.

\section{The design of the informatization solution of scenic spots under the mode of iot}

In the whole tourism industry chain, tourism scenic spots occupy the status of the center link as well as the key and core element of tourism industry. The role and impact of tourism scenic spots on 
the development of tourism industry are very important. Introducing advanced iot technology in daily operation pattern of scenic spots often will make the management of scenic spots have substantive changes. As for the development of iot informatization operation mode of scenic spots, firstly the comprehensive development and design on the infrastructures and integrated application platform should be conducted. The first step is the design on hardware, mainly including $3 \mathrm{~s}$ platform, security center, data center, and other infrastructures. Among them $3 \mathrm{~s}$ platform refers to RS remote sensing satellite, the GPS global positioning system and GIS geography information system. While the infrastructures generally include LAN, wan, wired communications and wireless communications. The second step is the design on data level. Here hardware is used to collect outside data. Hereafter is the step of analysis and processing of collected data on data level, and completion of network data interaction and sharing. The third step is the design on application level. After receiving the data processed from the data level, the application level will transmit these data information to all application systems of the tourism scenic spots and fully dig out the application functions of these data. Under this basis, the scenic spots' corresponding management centers will make scientific and rational decisions through their respective application systems. Under normal circumstances, the basis of construction of the application level lies in actual demand of scenic spots. Therefore the designs of application are different according to scenic spots with different application requirements. But in the overall tourism iot informatization design, all kinds of travel resources such as travel agencies, scenic spots, catering, shopping, hotel, entertainment and transportation etc. will be integrated. Taking advantage of this kind of iot integration marketing mode, sales cost of the scenic spot and its related subsidiary resources can be reduced greatly so as to realize the globalization and the dimension of sales and promotion of tourism resources, further strengthening the tourism management efficiency. In addition, the development of tourism resources informatization integrated marketing mode under the Internet of things mode make the sales scale of scenic spots have a significant expansion, realizing great money drawing of scenic spots under the basis of scenic spots protection, further providing a reliable source and guarantee of funds for the scenic spots on scenic spots management and resource protection. This can also lead to an improvement in scenic spots' focusing more on the brand image so as to attract more foreign and domestic tourists and further promote the health efficient and sustainable development of tourism.

\section{The application of RFID in tourism scenic spots}

RFID informatization technology on tickets.

Application of RFID technology in tourism scenic spots' tickets can not only have effective identifications on illegal tickets, but also increase the unique anti-counterfeiting function and other consumer intelligent function of tickets such as fixed-point top-up. At present, within the scope of the world there are two main forms of RFID tickets in scenic spots: wrist strap type and paper tickets embedded with RFID chips, of which the wrist-strap type tickets are relatively widely used in some scenic spots and theme parks abroad. Tickets of this type have security and payment function themselves. Compared with traditional tickets, they can provide visitors with more convenient payment forms and channels for consumption, to a great extent, promoting the increase of business income in tourism scenic spots. Within the scenic area, in general, under the premise of universal coverage of Wifi network, wireless POS within the scenic spots can be deployed with fast device speed and low cost, which can provide convenience for tourists to use wrist-strap type tickets. In addition, the wrist-strap type tickets also have simple positioning function, able to display its area location to tourists in real time and dynamically so as to be convenient for visitors to visit scenic spots better. Compared with the traditional paper tickets, the ticket system with paper embedded with RFID chip still use the same ticket process. The difference is the introduction of RFID bar code printer in this ticket system, with hardware system upgraded. Typically, RFID tickets system will monitor the state of the use of tickets strictly until the tickets invalid in order to effectively avoid the ticket payment avoidance or counterfeit in tourist scenic spots.

Whether wrist-strap type tickets or paper tickets embedded with RFID chips, the principles of which at last are embedding RFID chips into the tickets to realize the tickets' functions of basic 
ticketing, positioning and consumption etc. As a result, installing the RFID card read equipment in the main roads and attractions within the scenic spots, completing the check-in and ticket statistics through reading the ticket information on the one hand can identify the authenticity of a ticket intelligently, on the other hand can assist the control and directing of tourists traffic, advantageous to the maintenance of public order of the scenic spots. In addition, the RFID tickets offers visitors a unified consumption form of swiping card in the scenic spots. This can help the realization of informatization and intellectualization in tourism scenic spots' consumption management.

\section{RFID digital technology of the tour guide.}

According to the survey, the demand of digital tour guide occupies a large proportion in the requirement of tourist for tourism scenic spot service. In combination with GPS, RFID, communications and information query display technology, traditional map road signs has got reasonable improvement. Digital guide mode is used to replace traditional voice guide mode of the scenic spots. This contributes to the realization of intelligent integrated management of guide device and thus can rapidly and timely update and release the related information such as the travel guide. The implementation scheme of digital guide pattern is mainly the customization of a kind of self-service communication terminal with embedded RFID read-write device to make it be integrated into various technologies such as RFID, GIS and GPS. And at the same time installing RFID tags with introduction information of scenic spots saved on guide signs of all scenic spots in the tourism scenic area and starting the digital guide mode of the scenic area. As a result, with the help of the automatic communication terminal, tourists feel more free and have more detailed understanding of the interested information, getting related tourism resources and activities so as to effectively enhance their own tour experience. In addition, developing electronic mapping system of the target scenic spots by using GIS and GPS technology can provide technical support and guarantee for the navigation service of the scenic area so as to help tourists to formulate satisfying and appropriate tourist routes.

\section{The iot monitoring system in tourism scenic area}

The iot monitoring system of the tourism scenic spots, in general, mainly includes the environmental monitoring system and security monitoring system, of which the subsystems of security monitoring system include entrance guard control system and video monitor system. The operating principle of video monitor system is using electronic probe to intake dynamic videos of main attractions, wickets, dangerous roads, ticket office, parking lot and service area, and sending the videos to tourist area monitoring center in the form of network transmission. Through the video monitor system, the monitoring center can control the state of traffic and public order at any moment and thus formulate scientific and effective management plan of the scenic spot. While the entrance guard control system is mainly setting some conditions in advance. When triggered, the warning device of the entrance guard control system would send out alarm sound message, etc. Deployment of entrance guard control system within the scenic spots can make the scenic spot effectively ensure the safety management in key areas. And the using of fingerprint identification technology, face recognition technology and RFID technology in the entrance guard system can integrate intelligent video surveillance and visual talk-back system on this basis. This can comprehensively improve the quality and safety of the tourism scenic spot monitoring. In addition, strengthening dynamic monitoring on buildings in scenic area and ecological environment such as geology, water, atmosphere, forest etc. in the scenic area, collecting and analyzing change information of related factors such as humidity and temperature. After this, organizing and evaluating the data information the system background. Taking the evaluation results as the decision basis, conducting more in-depth research and development on the scenic spots on the basis of protecting the scenic spots.

\section{Tourist traffic informatization under the iot mode}

Generally speaking, in order to increase the satisfaction of the tourists to promote the healthy development of tourism as a whole, tourist traffic tends to require achieving highly sharing of 
information resources. The accuracy of information and traffic safety can help visitors have their travel plans planned better. It can satisfy tourists' use and scheduling of vehicles, giving visitors a safe trip. Perform system of tourist traffic vehicle tracking scheme mainly includes the central information system, vehicle terminal system and Car CCTV system, the main adopted technologies of which are mobile communication technology and RFID technology, of which the Car CCTV system is able to transmit real-time video or image to the central information system, effectively preventing crime or theft accidents. While the vehicle terminal system is integrated with GSM/GPRS and GPS, able to transmit the real-time location of the vehicle tracking information to the centralized information system. After receiving the vehicle positioning data, the centralized information system will show the street map which has the note of the location of the vehicle to the administrative staff through the screen so as to realize information monitoring and management of vehicle team in tourism scenic spots.

At present, most scenic spots in our country has the problem of management difficult of parking lot. In order to ensure continuing operations of certain spots, related staff of the parking lots are often required to have shift guard within 24 hours, especially under the condition that the scenic area parking area is relatively large, volume of business of staff such as charging and monitor etc. will increase substantially, thus prolonging the visitors' waiting time. In this case, the tourists' randomly in and out, queuing congestion phenomenon appear easily, which increasing the safe hidden troubles in the tourism scenic spots. While controlling the ins and outs of tourists and vehicles by application of RFID iot technology, realizing informatization and systematization of traffic management and parking fees of parking lots in tourism scenic area can effectively save the manpower resources of the scenic spots and make the efficiency of parking lot get comprehensive improvement. At the same time, combining with the video monitoring system, conducting intelligent monitoring on the vehicles and personnel in and out. In addition, in order to further enhance the security protection of the parking lots in traveling scenic area, face recognition and fingerprint recognition technology can also be introduced in the system. All in all, tourism information tracking location under the mode of iot on the one hand can help the realization of dynamic control of tourist transportation status and the status of the vehicle allocation of resources and matching the most scientific and appropriate tourist routes by tourism enterprises, on the other hand convenient for visitors to have visual query of all kinds of information of tourist traffic, enhancing tourists' satisfactions and making the operation of tourism enterprises have high efficiency and low cost, realizing the development of tourism traffic informatization model under the iot mode.

\section{Conclusion}

To sum up, the development of tourism informatization mode under iot mode, in essence, is to require supreme service and complete information in tourism scenic spots. In other words, the tourism scenic spots transfer scenic spots' information tourists want to the hands of customers timely by using advanced communication equipment, providing tourists with safe and complete sightseeing guarantees so as to effectively increase the tourists' satisfaction degrees. Implementation of iot informatization mode in tourism scenic spots can make substantial changes of ticket management, vehicle management, tourist safety management, traffic management and resource management of the scenic spots etc. in the scenic area, making scientific and effective control of the traffic in the scenic area. It can predict sudden emergencies and take steps to respond and handle in time under the basis of protecting the scenic area, really realize the intellectualization and informatization management of scenic spots, thus greatly promote the healthy and sustainable development of tourism in our country.

\section{References}

[1] ChengLiJun. Wisdom tourism development study under the information technology condition, Journal of commercial economy, 2014, (22) : 87-91. 
[2] Hangzhou city development and reform commission. Hangzhou opened the new model of "wisdom tourism", Journal of Zhejiang economy, 2015, (23): 134-135.

[3] Zhao Liqin, Li Zhongwen. Research on building the tourism development model of wisdom tourism takes serving the tourists as the core, Journal of Chengdu university (social science edition), 2014, (1) : 97-102.

[4] Yin Liying, Wei Ming. Telecom operators iot business model construction - based on Oswald framework, China's circulation economy, 2013, (6): 134-135.

[5] Niu Li Cheng. Tourism informatization model research under Iot mode, Journal of China commerce and trade, 2014, (19): 97-102. 